\section{ENVIRONMENTAL HEALTH}

\section{Heart unhealthy ozone}

Environ. Health Perspec. http://doi.org/c6w8 (2019).

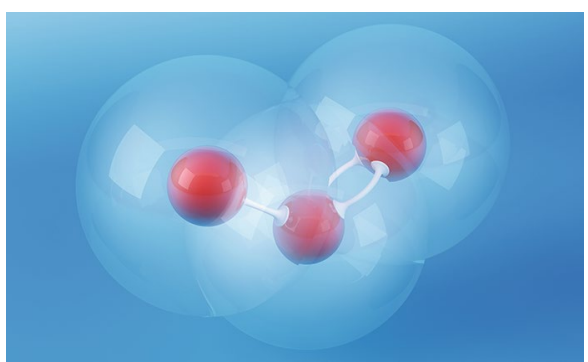

Credit: FrankRamspott/E+/Getty

Although there is strong evidence for negative respiratory effects from long-term ground-level ozone $\left(\mathrm{O}_{3}\right)$ exposure, evidence for a relationship between exposure and cardiovascular disease remains uncertain, and the physiological mechanisms underlying a potential link remain underexplored.

Meng Wang, of the University of Buffalo, and colleagues at the University of Washington and University of Wisconsin, use the Multi-Ethnic Study of Atherosclerosis to assess the longitudinal relationship between exposure to residence-specific $\mathrm{O}_{3}$ concentrations and indicators of coronary heart disease and stroke risk in adults. They show that cumulative exposure to $\mathrm{O}_{3}$ is associated with the progression of intimamedia thickness of the common carotid artery and carotid plaque burden, independent of exposure to other air pollutants (such as $\mathrm{PM}_{2.5}$ and $\mathrm{NO}_{2}$ ). The results are robust to a range of controls for cardiovascular disease risk and suggest different pathways and relative potencies for ozone and particulate matter on cardiovascular disease.

While ground-level ozone has declined in some places, it is anticipated to continue its overall increase with climate change and to continue to impact human health into the future.

https://doi.org/10.1038/s41558-019-0521-X

\section{TROPICAL CYCLONES}

\section{Further poleward influence}

J. Climate http://doi.org/c6xb (2019).

Nearly half of all Atlantic tropical cyclones turn into extratropical cyclones as they move poleward. This process is called extratropical transition (ET), and some of the most destructive recent Atlantic hurricanes underwent such a conversion. Hurricane Irene, in 2011, was one such example, but how ET for storms like this might change in a warmer world is still an open question.

Chunyong Jung and Gary Lackmann, of North Carolina State University, USA, used Weather Research and Forecasting (WRF) model experiments integrated at various levels of complexity to compare Irene's observed ET to its equivalent in a warmer climate. They found that in a highend warming scenario, the storm featured substantially heavier precipitation owing to increased moisture convergence and ocean evaporation, and ET was more intense due to lower pressure at the storm's centre and stronger surface winds. Importantly, ET lasted about $60 \%$ longer, meaning the

As the world rapidly urbanises, city design can play an important role in climate mitigation. However, city design also needs to consider adapting to avoid extreme temperatures caused by urban heat islands (UHIs). This can be achieved by designing low density, or non-compact, cities; but these come with greater greenhouse gas emissions from transport and the building sector, compared to compact cities.

To determine the optimal city design in light of these contrasting outcomes, Carl Pierer and Felix Creutzig, of Technical University Berlin, and Mercator Research Institute on Global Commons and Climate Change, Berlin, develop a geometrical optimization framework and model which design is best for both mitigation and adaptation. They report that star-shaped cities, with linear transit axes, allow low-carbon public transport, as well as reducing urban heat stress and emissions.

A greater number of axes increases UHIs, whereas emissions decrease. The optimal design needs to consider transport costs; medium to high fuel taxes correspond to low emissions and acceptible UHI effects, if the number of axes is small. These findings can inform rapidly developing regions on how to create liveable and sustainable cities. $B W$

https://doi.org/10.1038/s41558-019-0523-8

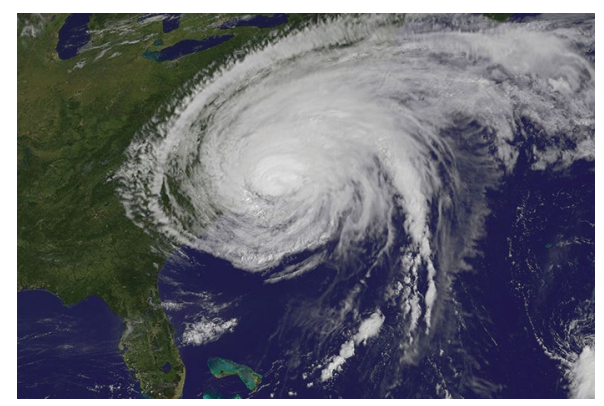

Credit: Stocktrek Images, Inc/Alamy Stock Photo

storm travelled a greater distance north as it transitioned. This result implies that a warmer world may change ET in a way that lures tropical cyclone-like conditions - and the havoc they wreak - further poleward. $B L$

https://doi.org/10.1038/s41558-019-0522-9

\section{INTERNATIONAL DEVELOPMENT}

\section{Energy aid emission costs \\ Environ. Sociol. http://doi.org/c6xf (2019).}

Wealthy governments base their strategies for providing aid to poor nations on a normative consensus on governance. Energy sector aid is typically framed as a means of generating economic growth, and is primarily based on investment in carbonbased energy infrastructure. While this development strategy may achieve donor goals of increasing access to reliable energy, doing so through fossil fuel use may have environmental consequences that are at odds with the goals of environmental international non-governing organizations (EINGOs).

Kent Henderson, from California State University, Bakersfield, analysed a panel dataset of 121 countries, from 1973 to 2011, to determine how the interaction between international development and environmental group interests impacts emissions in energyaid recipient countries. He found that increased energy sector aid is associated with higher $\mathrm{CO}_{2}$ emissions. However, this emissions effect from energy aid is reduced in countries with more ties to EINGOs, suggesting that pressure from environmental organizations to protect the environment, offsets emission increases from energy development. Thus, contradictory norms between energy development and environmental protection force world polity to mitigate its own negative environmental effects.

https://doi.org/10.1038/s41558-019-0524-7 